Ensino, Saúde e Ambiente - V5 (3), pp. 26-43, dez. 2012

\title{
ABORDAGEM SOCIOCULTURAL DE SAÚDE E AMBIENTE PARA DEBATER OS PROBLEMAS DA DENGUE: UM ENFOQUE CTSA NO ENSINO DE BIOLOGIA
}

\section{SOCIOCULTURAL APPROACH TO HEALTH AND ENVIRONMENT TO DISCUSS THE PROBLEMS OF DENGUE: A FOCUS ON TEACHING OF BIOLOGY STSE}

\author{
Daniele Blanco Cavalcanti; Jorge Lemos e Álvaro Chrispino \\ Centro Federal de Educação Tecnológica Celso Suckow da Fonseca (CEFET/RJ)
}

\section{RESUMO}

Realizamos um estudo de caso, onde a pesquisadora atuou como observadoraparticipante, que consistiu na aplicação de uma Unidade Didática, norteada pela Educação Ambiental para a Sustentabilidade e pelo enfoque Ciência-TecnologiaSociedade-Ambiente, utilizando a dengue como contexto. Participaram deste, três turmas do segundo ano do Ensino Médio, em um Colégio Estadual no Rio de Janeiro, no primeiro semestre de 2011. Aplicamos cinco atividades que resultaram em documentos produzidos pelos educandos, tratados utilizando a Análise de Conteúdo Temática. A categorização buscou estabelecer a organização dos dados em bruto e, para determiná-la, tomamos por base a generalidade dos textos produzidos, que passaram por um recenseamento, segundo a frequência da presença de certos itens. Procuramos levantar as percepções socioambientais, ampliar a visão das interações CTSA e aproximar o conteúdo propedêutico da realidade dos educandos. A visão redentora da ciência predominou. Em relação a dengue, notamos que muitos possuem fragilidades conceituais, porém, já refletem sobre atitudes preventivas. Sob o aspecto da sustentabilidade, os mesmos ampliaram as percepções referentes à problemática ambiental, iniciando um processo de questionamento, acrescentando maior criticidade em relação ao tema.

Palavras-chave: Dengue; Sustentabilidade; CTSA.

\begin{abstract}
The case study consisted of applying a Curriculum Unit, guided by the Environmental Education for Sustainability approach and the Science-Technology-SocietyEnvironment, using the dengue context. Participated in the three classes of high school in a State School in Rio de Janeiro, in the first half of 2011. We applied five activities that resulted in documents processed using qualitative analysis. The categorization established the organization of the data, we based the majority of texts that have gone through a census, according to the frequency of certain items. We seek to raise the social and environmental perceptions, improve vision CTSA interactions and approximate content of the reality of introductory students. The redemptive vision of science prevailed. For dengue, we noticed that many have conceptual weaknesses, however, already reflect attitudes about preventive measures. Under the aspect of sustainability, they broadened the perceptions and begin a process of questioning, adding more critical in this regard.
\end{abstract}

Key words: Dengue; Sustainability; STSE. 


\section{Introdução}

Vivemos em plena uma crise global de caráter socioambiental (Jacobi,2006), constituindo uma autêntica emergência planetária(Gil- Pérez e Vilches, 2006). Diante desta realidade, muitos indivíduos não perceberam a dimensão global de problemas socioambientais, inclusive os estudantes do Ensino Médio. Sob este aspecto, recordamos a necessidade do debate de temas como epidemias, fome e alterações climáticas na Educação Básica, de forma a inserir os conteúdos propedêuticos no contexto de vida dos educandos.

A Educação Ambiental (EA) surgiu em uma época de grande mobilização social, gerada pelos impactos do progresso científico e tecnológico. Nesse mesmo período, nascia o movimento Ciência-Tecnologia-Sociedade (CTS), que objetivava analisar os benefícios e prejuízos causados pela ciência e tecnologia no âmbito social. Segundo Vasconcelos e Santos, no decorrer dos anos a sigla foi alterada para CTSA, referindo-se especificamente aos impactos da tecnociência no meio ambiente (Vasconcelos e Santos, 2008). Conforme Freitas (2006), a EAS ganhou importância a partir da Conferência da Tessalônica e após a Cimeira de Johanesburgo. Com advento desses, a EAS tornou-se um caminho estratégico a ser percorrido pelas sociedades para o alcance do sustentabilidade.

Defendemos a realização de atividades articulando o enfoque CiênciaTecnologia-Sociedade-Ambiente e a sustentabilidade adotando a dengue como tema socioambiental.

A dengue é a arbovirose que se encontra amplamente distribuída nas Américas, graças a situações socioambientais que contribuem para a proliferação do vetor (Sperandio, 2006; Tauil, 2002). Seu principal vetor, o Aedes aegypti, encontrou no contexto atual, condições favoráveis para sua expansão, entre estas destacamos a deficiência dos serviços de abastecimento de água e de limpeza urbana, a utilização de recipientes descartáveis e as mudanças climáticas (Brasil, 2002). Tais fatores descritos contribuíram para a escolha do tema, que encontrou maior relevância, visto que percebemos a ausência de dissertações e teses enfocando a EAS articulada ao enfoque CTSA para o desenvolvimento de atividades de biologia utilizando a dengue como contexto. Isso foi percebido a partir de levantamento das pesquisas realizadas no intervalo entre 2000 e 2010, disponíveis no Banco de Teses da Capes, utilizando as seguintes combinações de palavras-chave: dengue e educação ambiental, dengue e CTS, dengue e ensino de ciências e dengue e educação para a sustentabilidade. 
Elegemos como questão de pesquisa: Como uma unidade didática de biologia, adotando a dengue como tema socioambiental, contribui para ampliar a percepção das interações CTSA presente nos alunos, aproximando o conteúdo de biologia da realidade destes?

\section{Métodos}

Caracterizamos esta investigação como um estudo de caso com abordagem qualitativa, onde procuramos extrair dos indivíduos imersos na pesquisa, os significados do objeto da mesma (Chizzoti, 2003). Aplicamos uma Unidade Didática (UD) durante as aulas de Biologia, envolvendo três turmas do segundo ano do Ensino Médio, de uma Escola Estadual em São João de Meriti no Rio de Janeiro, durante o primeiro semestre de 2011.

Utilizamos a Unidade Didática (UD) como estratégia didática, objetivando analisar momentos reais de aprendizagem, onde pesquisadora e alunos buscam através do diálogo e do auxílio mútuo reformular conhecimentos prévios. Segundo Freshi e Ramos (2009) a UD objetiva a superação do planejamento linear, vigente na maioria dos currículos atuais e manuais didáticos. Pereira, Basso e Borges (2008) definem UD como uma metodologia que supera o ensino tradicional, onde o professor atua como mediador apresentando uma visão geral do trabalho orientando os alunos. Segundo os autores, a UD oferece ao aluno a oportunidade de questionar, discutir, buscar respostas e organizar a comunicação dos resultados em um processo participativo. Concordamos com Galliazi, Garcia e Lindemann (2004) que defendem o uso de unidades didáticas como forma de superação da réplica da sequencia de conteúdos, as quais geralmente são oferecidas pelo livro didático. Iniciamos a UD com aplicação de um questionário aberto e posterior exposição sobre as relações CTSA. Dividimos as turmas em grupos, os grupos buscaram exemplos da atualidade sobre as interações CTSA, e explicaram oralmente as inter-relações entre Ciência, Tecnologia, Sociedade e Ambiente. Na segunda atividade, realizamos a leitura e discussão da revista intitulada Maluquinhos contra a Dengue 2 e a turma foi dividida em grupos, cada um ficando responsável pela elaboração de um texto ou revista em quadrinhos, que deveria descrever os sintomas, a forma de transmissão da doença e propor uma mobilização social para o combate ao mosquito vetor.

Nas demais aulas, analisamos gráficos e tabelas sobre a incidência da dengue no Brasil, disponíveis na página eletrônica do governo sobre a dengue. Procuramos dar ênfase nesta atividade: às relações existentes entre fatores climáticos, sociais e 
econômicos, ao caráter interdisciplinar e amplo da temática em estudo, bem como, às discussões sobre possíveis benefícios ou prejuízos decorrentes do progresso tecnológico e científico. No decorrer do segundo bimestre, os alunos realizaram mediante orientação da professora e pesquisadora, a confecção de pequenos vídeos educativos sobre prevenção da dengue, envolvendo a comunidade escolar e o entorno. Participaram desta atividade diretamente um total de 60 alunos, formando 6 grupos de 10 educandos. Foram elaboradas entrevistas com as pessoas da comunidade, no interior da escola os alunos encenaram e filmaram um jornal sobre a dengue, e além disso, nas proximidades do colégio os mesmos conversaram com alguns moradores sobre a importância do trabalho os quais colaboraram falando sobre os problemas da região. Para finalizar a UD, foi exibido o vídeo Aedes aegypty e Aedes albopictus-Uma ameaça aos trópicos (FIOCRUZ), com posterior discussão e aplicação de um questionário aberto relacionando a doença e o enfoque CTSA, com objetivo de avaliação.

Os dados foram tratados de acordo com a Análise de Conteúdo (AC). Optamos por realizar uma análise temática, adotando um enfoque socioambiental da Dengue como unidade de registo, o qual consiste em determinar os núcleos de sentido, cuja frequência de aparição, pode significar algo para o objetivo escolhido (Bardin, 2010). Realizamos a forma mais simples de $\mathrm{AC}$, que consiste na contagem da frequência de todas as características codificadas no texto.

\section{Resultados e discussão}

Aplicamos primeiramente um questionário com perguntas abertas, para levantar e analisar as percepções socioambientais dos educandos.

\section{Atividade 1}

1- O que é meio ambiente?

Sauvé (2005) define meio ambiente como a própria trama da vida, onde se encontram natureza e cultura forjando nossa identidade, e estabelecendo nossas relações com o mundo. Tomando como norte esta definição de meio ambiente, percebemos que muitos alunos não se reconhecem parte integrante desse, muito menos compreendem as variadas interações CTSA existentes.

Analisando a visão de meio ambiente dos envolvidos, observamos que 56,5\% (52) restringem o meio ambiente a componentes bióticos e abióticos do ecossistema. As categorias foram estabelecidas não somente a partir da leitura e análise das respostas, mas tomando como base a definição de meio ambiente estabelecida por Sauvé em seu 
estudo Cartografia da Educação Ambiental (Sauvé, 2005). Dentre os envolvidos 34,7\% (32), começam a perceber a cidade e todas as relações que ocorrem nesta, como integrantes do meio ambiente, e uma parcela reduzida $(8,6 \%-8)$ define meio ambiente como local degrado.

2- A dengue pode ser considerada um problema socioambiental? Justifique sua resposta.

Dentro do universo pesquisado não existiram relatos relacionando a doença a um problema socioambiental, no entanto $80,6 \%$ (74) caracterizam a dengue como um problema social, enquanto somente 19,35\% (18) acreditam que a doença também possa ser considerada um problema ambiental. Os respondentes relatam a existência de criadouros em locais onde o lixo é acumulado de forma inadequada, acarretando acúmulo de água, onde o mosquito se desenvolve. Os envolvidos na pesquisa relacionaram a proliferação do mosquito somente a períodos de chuva, destacando o verão como período de maior incidência, devido à pluviosidade.

3- Os progressos da ciência e da tecnologia diminuem os problemas ambientais e melhoram as condições de vida da sociedade? Justifique sua resposta.

Do total de participantes, 64,14\% (59) relatam que os avanços da tecnociência beneficiam a todos e não causam nenhum tipo de prejuízo, tal concepção é conhecida como perspectiva salvacionista e redentora da ciência-tecnologia (Auler, 2003). Sob este aspecto, Daza-Caceido (2011) assinala que esta visão otimista relacionada aos avanços da CT é comum entre os jovens, independente de seu país de origem. Essa visão observada durante a análise dos resultados, muito provavelmente deve-se a forma como a ciência é tratada nas escolas durante a educação básica, que segundo Acevedo et al (2005) costuma ser uma imagem da ciência acadêmica do passado .

Dentre os benefícios destacados pelos alunos relacionados ao progresso da ciência e da tecnologia, citamos: a produção de remédios e vacinas, o computador, carros com combustíveis menos poluentes e a praticidade gerada pelo aumento do luxo e do conforto. Uma parcela dos respondentes, 19,56\% (18) assinalam os impactos negativos causados pelo progresso da ciência e da tecnologia sobre o meio ambiente, em contrapartida ressaltam a praticidade e o conforto decorrente do progresso. Destes $16,3 \%$ (15) acreditam que o progresso da ciência e da tecnologia atua unicamente de forma negativa.

4- Do conjunto da sociedade, os cientistas são os mais preparados para dizer o que devemos fazer para melhorar o meio ambiente? 
Quase a totalidade dos educandos, 95\% (87) consideraram os cientistas mais preparados que as demais pessoas para resolver os problemas ambientais, assim na visão destes os cientistas são os únicos responsáveis pela construção do conhecimento científico neutro, legitimando o modelo tecnocrático. Esta visão do cientista como um gênio dotado de grande conhecimento, é caracterizada por Gil-Pérez et al (2001)como uma visão deformada da ciência, individualista e elitista, como se as decisões isoladas de um cientista fossem capazes de resolver qualquer problema.

Lembramos que o enfoque CTS destaca como principal finalidade da educação científica, a participação social nas decisões tecnocientíficas. Dentro deste aspecto, Ríos e Solbes (2007) complementam o raciocínio, destacando a importância do tratamento das interações CTSA para propiciar aos alunos uma visão contextualizada e crítica da tecnociência.

5- Explique com suas palavras as relações existentes entre Ciência, Tecnologia, Sociedade e Meio Ambiente.

Os alunos tiveram dificuldades para compreender as relações CTSA, 8,28\% (9) desses deixaram a questão em branco e $25 \%$ (23) responderam palavras soltas e vagas. Provavelmente essa dificuldade resida no fato de terem passado grande parte de suas vidas, recebendo uma educação conteudista e descontextualizada. Sob este enfoque Cachapuz et al(2005), acrescentam que o Ensino de Ciências muitas vezes transmite uma visão descontextualizada e socialmente neutra, ignorando as relações CTSA . Entre os envolvidos, 53,8 \% (49) possuem uma visão redentora da ciência e da tecnologia, acreditando que ambas apenas trazem benefícios e que quanto maior o progresso da ciência e da tecnologia, maior será o bem estar da sociedade. Podemos tentar traduzir o pensamento dos alunos da seguinte forma: o desenvolvimento científico (DC) propicia desenvolvimento tecnológico (DT) que gera desenvolvimento econômico (DE) determinando o desenvolvimento social (DS), visão conhecida como modelo linear do progresso (Auler, 2002). A praticidade trazida através dos equipamentos eletrônicos é relatada por $11,9 \%$ (11) dos discentes, entretanto os mesmos destacam os impactos negativos decorrentes de atividades relacionadas à Ciência e Tecnologia no meio ambiente.

\section{Atividade 2}

Realizamos a leitura e a discussão sobre a revista Maluquinhos contra a Dengue $2^{1}$, posteriormente a turma foi dividida em grupos, cada qual responsável pela

\footnotetext{
${ }^{1}$ Disponível em: http://www.riocontradengue.com.br/conteudo/maluquinho.asp Acesso: 10/02/2011
} 
elaboração de um texto ou revista em quadrinhos sobre a dengue. A elaboração desse material pelo grupo deveria descrever os sintomas, a forma de transmissão da doença, além de propor uma mobilização social para o combate ao mosquito vetor. Do material produzido, quinze documentos foram submetidos à análise de conteúdo temática. Apenas os textos foram analisados. As categorias foram elaboradas levando em consideração a relevância dos conteúdos de Biologia para a vida prática dos alunos, permitindo a co-ocorrência de subcategorias(Tabela 1).

Podemos destacar que a análise dos textos produzidos evidenciou o início de uma reflexão referente à responsabilidade compartilhada entre população e governo diante da prevenção da doença. A doença é descrita pelos envolvidos como uma doença viral grave, de caráter epidêmico que pode levar à morte, já que ainda não apresenta remédio para curá-la. Os mesmos acreditam que o tratamento se reduz ao controle dos sintomas e à prevenção de complicações. Tal fato foi descrito em $20 \%$ dos trabalhos confeccionados pelo grupo. Na pesquisa realizada por Araújo, Araújo-Jorge e Meirelles (2005) os alunos envolvidos definiram a dengue de forma bastante reduzida apenas como uma doença (56\%), enquanto somente $15 \%$ classificaram a doença como letal. O mosquito é descrito como urbano e somente as fêmeas são citadas como hematófagas. Em relação à transmissão da doença, 33,3\% (5) dos trabalhos, descrevem o Aedes aegypti como mosquito transmissor da dengue. $\mathrm{O}$ despreparo dos médicos para o diagnóstico da doença é relatado como um dos fatores que propiciam o óbito. Segundo Tauil (2001), o diagnóstico precoce da doença não tem sido a regra e com frequência seus sintomas são confundidos pelos médicos com os de outras doenças. Na estória em quadrinhos elaborada por um dos grupos, chamada de "Esquadrão contra a Dengue", o conceito de epidemia é utilizado de forma incorreta como se a mesma fosse restrita somente a Baixada Fluminense, o que pode ser um indício de que alguns desconhecem a grande faixa de distribuição do mosquito, bem como a gravidade do caráter epidemiológico da doença.

Tabela 1-Categorias ilustradas nos textos produzidos pelos alunos

\begin{tabular}{cccc}
\hline Categorias & Subcategorias & Ocorrência & Percentual \\
Transmissão & Através da picada do & 5 & $33,3 \%$ \\
mosquito & & \\
\hline Gravidade da & Internação & 4 & $26,6 \%$ \\
\hline
\end{tabular}




\begin{tabular}{|c|c|c|c|}
\hline \multirow[t]{2}{*}{ doença } & Epidemia & 5 & $33,3 \%$ \\
\hline & Morte & 3 & $20 \%$ \\
\hline \multirow[t]{6}{*}{ Criadouros } & Piscina & 3 & $20 \%$ \\
\hline & Pneus & 7 & $46,6 \%$ \\
\hline & Garrafas & 6 & $40 \%$ \\
\hline & Lixo & 3 & $20 \%$ \\
\hline & Caixas d'água & 9 & $60 \%$ \\
\hline & Vasos de planta & 9 & $60 \%$ \\
\hline \multirow[t]{7}{*}{ Prevenção } & Não deixar pneus na chuva & 7 & $46,6 \%$ \\
\hline & Mobilização social & 5 & $33,3 \%$ \\
\hline & Tampar a caixa d água & 9 & $60 \%$ \\
\hline & Notificação a prefeitura & 2 & $13,3 \%$ \\
\hline & Pôr areia nos pratinhos de & 9 & $60 \%$ \\
\hline & planta & & \\
\hline & $\begin{array}{c}\text { Manter as garrafas } \\
\text { tampadas }\end{array}$ & 9 & $60 \%$ \\
\hline \multirow[t]{2}{*}{ Responsabilidade } & Governo & 2 & $13,3 \%$ \\
\hline & População & 10 & $66,6 \%$ \\
\hline
\end{tabular}

Fonte: acervo da autora

Quando os vasos de plantas foram relatados como criadouros em um dos trabalhos analisados, o grupo assinalou a possibilidade de visualizar os ovos do mosquito neste recipiente, o que pode ser considerado uma concepção alternativa, já que estes não são visíveis macroscopicamente. Em relação à prevenção, destacam a importância da atuação da população, da escola e do governo para a transmissão de informações a respeito da doença, assim como a importância da implantação de campanhas envolvendo agentes de saúde e a população para a eliminação de focos. Foram relatadas como atitudes importantes para a prevenção da doença: colocar terra ou areia nos pratinhos de plantas, lavar e tampar as caixas d'água, limpar piscinas e colocar 
a quantidade correta de cloro, usar repelentes, não deixar água parada e colocar as garrafas com o gargalo para baixo. A notificação de locais abandonados com focos na prefeitura é relatada como de extrema importância, o que pode ser visto como um indício de que o grupo envolvido começa a se perceber como cidadão de direito e acredita na importância da mobilização social. Dentro deste aspecto, a escola é vista como um local de transmissão de informação que deve ser colocada em prática pelos participantes.

\section{Atividade 3}

Durante a mesma analisamos mapa (figura 1) e tabela sobre a incidência da dengue no Brasil, disponíveis na página eletrônica do governo. Procuramos enfatizar: as relações existentes entre fatores climáticos, sociais e econômicos, o caráter interdisciplinar e amplo da temática em estudo, bem como discussões sobre possíveis benefícios ou prejuízos decorrentes do progresso tecnológico e científico. Cada grupo de 6 alunos recebeu um questionário com duas questões ,participaram desta, 102 educandos, produzindo 17 documentos.

1-Analise o mapa do Brasil com os casos de dengue, e descreva quais prováveis motivos contribuíram para a doença proliferar por quase todo o país.

Figura 1- Casos de Dengue no Brasil

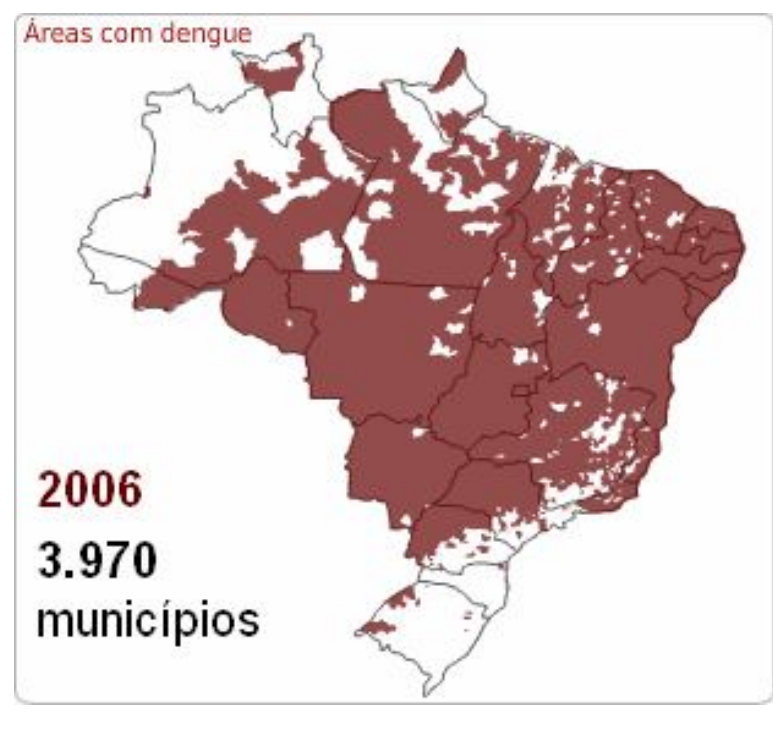

Fonte: http://www. dengue. org.br

Esta questão foi formulada visando verificar como os educandos percebiam os aspectos da relação saúde-doença. Os participantes atribuíram a expansão da doença pelo Brasil aos seguintes fatores: descaso do governo e da população (6-35,29\%), falta de prevenção por parte da população (3-17,6\%), descaso da população e clima favorável 
(3-17,6\%) e trânsito de pessoas contaminadas de um estado para o outro (3-17,6\%). Duas respostas consideradas foram descartadas (2-11,7\%). Com base na análise dos resultados, observamos uma percepção parcial das variadas nuances que abrangem o tema em estudo, o que segundo Gil-Pérez e Vilches (2006), resulta da falta de tradição do sistema escolar abordar problemas em seus aspectos globais. Na categoria descaso do governo e da população, os alunos enfatizaram o problema da carência de saneamento básico, e relataram o hábito da população descartar lixo em local inadequado o que aumenta o número de possíveis criadouros para o mosquito, onde a água provavelmente pode acumular e se tornar um local viável para o desenvolvimento do ciclo biológico do vetor. Também foram citadas a falta de pavimentação das ruas e de drenagem dos rios. Os alunos envolvidos relataram como descaso da população a reduzida participação no combate ao mosquito vetor. Em relação ao clima, destacaram a existência de temperaturas elevadas e da pluviosidade o que favorece $o$ desenvolvimento do mosquito, consequentemente aumentando o número de casos.

2 - Observe a tabela referente ao Levantamento rápido do índice de infestação por Aedes aegypti 2010 (LIRA) realizado no Rio de Janeiro, e responda:

a- Quais os criadouros encontrados em São João de Meriti ?

b-Como o município é classificado?

Tabela 2-A classificação dos municípios e os criadouros predominantes

\begin{tabular}{cccc}
\hline Município & IIP $(\%)$ & Classificação & Criadouros predominantes \\
\hline Belford Roxo & 0,90 & Baixo risco & Tambor, barril e tonel \\
Duque de Caxias & 1,60 & Alerta & Tambor, barril e tonel \\
Itaguaí & 2,80 & Alerta & Lixo \\
Japeri & 0,80 & Baixo risco & Vaso de planta \\
Magé & 0,30 & Baixo risco & Lixo \\
Mesquita & 0,60 & Alerta & Tambor, barril e tonel \\
Nilópolis & 0,70 & Alerta & Tambor, barril e tonel \\
Nova Iguaçu & 1.70 & Alerta & Tambor, barril e tonel \\
Queimados & 1,10 & Alerta & Tambor, barril e tonel \\
& & & (depósitos para armazenamento \\
\hline
\end{tabular}


Ensino, Saúde e Ambiente-V5 (3), pp. 26-43, dez. 2012

\begin{tabular}{cccc}
\hline & & & de água). \\
Rio de Janeiro & 2.40 & Alerta & Lixo \\
São João de Meriti & 1,00 & Alerta & Tambor, barril e tonel \\
Seropédica & 1.40 & Alerta & Tambor, barril e tonel \\
\hline
\end{tabular}

Fonte: http://www.dengue.org.br

Os alunos destacaram a existência de criadouros predominantes, como tambor, barril e tonel (Tabela 2), apenas um dos grupos acrescentou a existência de rios e valões. Consideramos a caracterização de rios e valões como possíveis criadouros, uma concepção alternativa muito provavelmente relacionada a forma como os mosquitos se propagam pela mídia. Na pesquisa realizada por Lefevre et al(2007) junto a moradores do litoral norte de São Paulo, os autores relatam que a água limpa, suja ou empoçada está associada para a população ao desenvolvimento do mosquito.

\section{Atividade 4}

Foram selecionados para a análise 6 vídeos, produzidos em grupo, cada um formado por 7 alunos. Foram abordados no material produzido pelos alunos, os seguintes tópicos: focos dentro e fora do colégio, prevenção, gravidade da doença, sintomas, distribuição geográfica do vetor, sorotipos e hábitos da comunidade. É importante destacar que a lista de tópicos foi definida pela professora junto aos alunos. Em relação aos focos, 2 vídeos relataram como possível criadouro para o mosquito concentração de água poluída, entretanto sabemos que o mosquito só desova em água limpa ou com o mínimo de matéria orgânica. Acreditamos que esse trabalho tenha motivado e auxiliado a desenvolver o senso de responsabilidade dos alunos, já que estes questionaram a existência de garrafas com água acondicionadas incorretamente no interior do colégio, bem como a existência de grandes poças no ambiente escolar. Após a análise dos vídeos, percebemos a confecção destes como um recurso motivador e capaz de propiciar a argumentação e a mobilização diante de temas de importância social, e de melhorar a compreensão de temas socioambientais como a dengue. Percebemos maior integração entre as turmas envolvidas e o despertar da importância por parte do grupo da mobilização social na busca de soluções embasadas. Dentro deste raciocínio, concordamos com Reis (2004), quando o mesmo destaca a necessidade da passagem progressiva do estado de cidadão passivo para o de cidadão ativo apto a participar de processos de tomada de decisão, e de avaliar as implicações do progresso científico e tecnológico na sociedade. 


\section{Atividade 5}

Para finalizar a UD, exibimos o vídeo Aedes aegypty e Aedes albopictus-Uma ameaça aos trópicos (FIOCRUZ) ${ }^{2}$, com posterior discussão e aplicação de um questionário aberto relacionando a doença e o enfoque CTSA, como objetivo de avaliação. Esta atividade foi desenvolvida no $2^{\circ}$ bimestre de 2010 , neste período parte dos professores da Secretaria Estadual de Educação estavam em greve, o que acabou interferindo no número de alunos participantes, com isso participaram desta atividade somente 27 alunos. Lembramos que as perguntas respondidas no questionário final foram realizadas individualmente, ao contrário das outras atividades.

1- Como a dengue é transmitida?

Um total de 70,3\% (19) se restringiu a responder somente pela picada do mosquito, enquanto 22,2\% (6) relataram que poderia ser tanto pelo Aedes aegypti, como pelo Aedes albopictus. Um número diminuto de participantes 7,4\% (2) afirmou que a doença era transmitida por água parada, o que configura uma concepção alternativa.

2-Quais as condições socioambientais que favorecem a proliferação do principal vetor da dengue?

Os alunos apresentaram dificuldade para responder esta pergunta, a maioria não conseguiu perceber as relações existentes entre meio ambiente, sociedade, saúde e doença, muitos somente destacaram a existência de possíveis criadouros, sem esclarecer os motivos para tal ocorrência. Do total de participantes, $46 \%$ (12) dos envolvidos identificaram como criadouros pneus, pratinhos de plantas, caixa d'água destampada e pratinhos de plantas. Enquanto 19\% (5) dos envolvidos descreveram a existência de terrenos baldios.

Dentre as condições socioambientais os alunos destacaram: alta densidade populacional, carência de saneamento básico, terrenos abandonados, moradias impróprias, chuvas e temperaturas elevadas (Tabela 3). Segundo Teixeira e Medronho (2008), o saneamento básico, principalmente o abastecimento de água, e a coleta de lixo são insuficientes nas periferias, gerando um aumento dos criadouros potenciais do Aedes aegypti. Nas proximidades da escola, podemos encontrar grande acúmulo de lixo. A partir da discussão gerada, sobre os problemas socioambientais da região, sob o enfoque da sustentabilidade, observamos que estes ainda possuem uma percepção reduzida das relações existentes entre meio ambiente, sociedade, qualidade de vida, direitos humanos, economia e política.

${ }^{2}$ Disponível em: http://www.fiocruz.br/ioc/cgi/cgilua.exe/sys/start.htm?sid=45 
Ensino, Saúde e Ambiente - V5 (3), pp. 26-43, dez. 2012

Tabela 3- Condições socioambientais que favorecem a proliferação do vetor

\begin{tabular}{|c|c|c|}
\hline Categorias & Ocorrência & Percentual \\
\hline $\begin{array}{l}\text { Acúmulo de lixo, água parada e aquecimento } \\
\text { global }\end{array}$ & 8 & $29,6 \%$ \\
\hline Temperatura e densidade populacional elevada & 5 & $18,51 \%$ \\
\hline $\begin{array}{c}\text { Garrafas pet, água parada, pneus, lixo, caixas } \\
\text { d'água destampadas, terreno baldio e temperatura } \\
\text { elevada }\end{array}$ & 10 & $37,03 \%$ \\
\hline Pobreza & 4 & $14,8 \%$ \\
\hline
\end{tabular}

Fonte: acervo da autora

3-Descreva o Aedes aegypti.

De acordo com Oliveira (2006), o Aedes aegypti apresenta cor escura, um desenho branco-prata em forma de lira no tórax e bandas brancas próximas as patas. Segundo a autora, o macho e a fêmea são muito parecidos. O mosquito foi descrito pelos alunos participantes dessa pesquisa, em sua maioria como preto e branco, com um par de antenas na cabeça, patas e um bico para sugar sangue. Algumas respostas resumiram-se apenas a coloração deste, enquanto outras deram uma descrição mais detalhada do mesmo.

4-Qual a distribuição geográfica do principal vetor da dengue?

Segundo Braga e Valle (2007), a dengue é endêmica na África, nas Américas, no Leste Mediterrâneo, no sudeste asiático e oeste do pacífico. Dentre os respondentes, 48,14\% (13) dos alunos afirmam que a epidemia se estende por toda América, Ásia, África e Oceania, enquanto 37,03\% (10) relata a existência do vetor somente no continente americano e africano. Talvez Ásia, África e Oceania tenham sido citadas por terem sido descritas no vídeo como locais de origem do Aedes albopictus e do Aedes aegypti. Um número reduzido de educandos, 14,8\% (4) afirmam que o mosquito só está presente em Minas Gerais e no Rio de Janeiro, baseado nisso podemos afirmar que apenas esse número reduzido de alunos não percebe a dimensão epidêmica do problema, possuindo uma visão mais fragmentada da problemática.

5-Como a Ciência, a Tecnologia e a Sociedade contribuem para a prevenção da dengue? 
Percebemos através da análise das respostas que a visão de tecnologia como ciência aplicada persiste, sendo esta adotada de forma clara nas categorias 2 e 5 (Tabela 4), tal visão constitui um dos mitos relacionados à CT. Podemos dizer que os alunos ainda não possuem uma visão adequada das interações CTS. A visão de tecnologia como ciência aplicada deriva de uma concepção filosófica e positivista característica dos anos 60 (Acevedo-Díaz et al,2003). Nesta visão, o desenvolvimento tecnológico depende hierarquicamente da investigação científica.

É interessante destacar que os alunos participantes em sua maioria percebem apenas o lado positivo da CT, olvidando os prejuízos que os inseticidas podem causar ao meio ambiente e a saúde humana consequentemente. Consideramos tal visão uma visão salvacionista da CT, a qual acredita que quanto maior o investimento em ciência e tecnologia, maior será o progresso econômico e o bem estar social. Defendemos a necessidade de propagar o ensino com enfoque CTS para, através deste, ampliar a participação social nos processos decisórios relacionados à influência da CT na sociedade, buscando romper a tecnocracia e preparar os envolvidos para a vivência em uma sociedade democrática. Dentro deste aspecto, Solbes e Vilches(2004) destacam que a participação cidadã na tomada de decisões, contribui para evitar a aplicação de inovações, das quais se desconhecem as consequências sobre a vida de todos.

Tabela 4- Percepções das relações CTSA adotando a dengue como contexto

\begin{tabular}{|c|c|c|}
\hline Categorias & Ocorrência & Percentual \\
\hline $\begin{array}{l}\text { 1-A ciência e a tecnologia contribuem } \\
\text { descobrindo meios de como acabar com o } \\
\text { mosquito da dengue. }\end{array}$ & 4 & $14,8 \%$ \\
\hline $\begin{array}{l}\text { 2-A ciência estuda as formas de prevenção } \\
\text { e a tecnologia transmite (através dos meios } \\
\text { de comunicação) informações sobre como } \\
\text { se proteger da doença. A sociedade faz a } \\
\text { sua parte. }\end{array}$ & 6 & $22,2 \%$ \\
\hline $\begin{array}{l}\text { 3-Produzindo inseticidas, vacinas e } \\
\text { realizando campanhas de combate ao foco. }\end{array}$ & 9 & $33,3 \%$ \\
\hline $\begin{array}{c}\text { 4-Fazendo passeatas para alertar a } \\
\text { população }\end{array}$ & 2 & $7,4 \%$ \\
\hline 5-A ciência estuda formas de & 6 & $22,2 \%$ \\
\hline
\end{tabular}


combate ao mosquito e a tecnologia

contribui com aparelhos para a produção de

remédios.

Fonte: acervo da autora

Percebemos a dengue como um tema de extrema importância, o qual pode ser bastante explorado dentro de uma abordagem CTS no ambiente escolar. Diante disso, caracterizamos a Unidade Didática aplicada como uma estratégia difusora da discussão socioambiental, onde adotamos a sustentabilidade, visando fortalecer valores coletivos e promover a participação na tomada de decisões fundamentadas. Concordamos com os referidos autores, quando estes assinalam, a necessidade do estabelecimento de espaços colaborativos para construção do conhecimento, o que constituiu um dos objetivos específicos desta pesquisa, o estabelecimento de comunidades de aprendizagem. Assim como Jacobi, Tristão e Franco (2009) percebemos que o caminho rumo a uma sociedade sustentável, permanece repleto de problemas, graças a uma reduzida compreensão da sociedade dos fatores que envolvem a situação de emergência planetária que estamos vivendo.

\section{Considerações finais}

A Unidade Didática (UD) aplicada possibilitou a análise das percepções socioambientais dos alunos e, ao longo da mesma, acarretou um maior envolvimento destes nas aulas, resultando em um aprimoramento dos conhecimentos de Biologia por parte do grupo, maior envolvimento nas aulas e maior criticidade. Durante a UD percebemos que a visão inicial de meio ambiente restrita a componentes bióticos e abióticos adotada por muitos alunos se ampliou, passando a incluir as relações sociais e seus impactos no meio ambiente. Os educandos destacaram a importância de aulas utilizando recursos lúdicos como quadrinhos e produção de vídeos, os mesmos demonstraram ao longo destas atividades 2 e 4, mais motivados. A abordagem e percepção dos alunos a respeito da interferência do ser humano no meio ambiente tornou-se mais clara a partir dos vídeos produzidos na atividade 4, onde os mesmos passaram a se sentir mais responsáveis e conscientes de sua atuação no meio, a partir de entrevistas com membros da comunidade escolar e do entorno. Destacamos a importância da utilização de recursos lúdicos como ferramentas úteis na promoção do ensino-aprendizagem. Consideramos que aulas com recursos variados, que explorem a criatividade do aluno e despertem uma maior motivação, podem ser adotas pelo 
professor na abordagem de temas com um maior interesse social, levando o aluno a se reconhecer como parte integrante do problema e impulsionando o mesmo na busca de possíveis soluções. Em relação à percepção destes sobre a dengue, o grupo ampliou sua compreensão sobre a problemática. Muitos assinalaram a importância da abordagem do tema integrando conhecimentos de outras disciplinas. Após a análise dos resultados concluímos que a UD embora tenha servido como contexto para conduzir os educandos a uma melhor compreensão do conteúdo de Biologia, a mesma ampliou de forma parcial a percepção das interações CTSA, despertando nos envolvidos a capacidade de argumentação e uma maior criticidade em torno da problemática dengue, além de ampliar a cultura científica destes.

\section{Referências bibliográficas}

Acevedo et al .Mitos da didática das ciências acerca dos motivos para incluir a natureza da ciência no ensino das ciências. Ciência \& Educação, 2005;11(1): 1-15.

Acevedo-Díaz et al. Creencias sobre la tecnología y sus relaciones con la ciência. Revista Electrónica de Enseñanza de las Ciencia. 2003; 2, (3): 353-376.

Araújo IC N, Araújo-Jorge TC, Meirelles, RMS. Prevenção à dengue na escola: concepções de alunos do ensino médio e considerações sobre as vias de informação. In: V ENCONTRO NACIONAL DE PESQUISA E EDUCAÇÃO EM CIÊNCIAS, 2005, Bauru. ATAS do V ENPEC, 2005.

Auler D. Alfabetização científico-tecnológica: um novo paradigma? Ensaio-pesquisa em Educação em Ciências, 2003, Mar ; 5(1):1-16.

Auler D. Interações entre Ciência-Tecnologia-Sociedade no contexto da formação de professores de Ciências. Tese (Doutorado em Educação) -Universidade Federal de Santa Catarina; 2002.

Bardin, L. Análise de Conteúdo. 4. ed. Lisboa: Edições 70, 2010. 281p.

Braga, IA; Valle, D. Aedes aegypti: histórico do controle no Brasil. Epidemiologia e Serviços de Saúde 2007; 16(2): 113 - 118.

Brasil. Ministério da Saúde. A Sociedade contra a Dengue/Ministério da Saúde, 2002.

Cachapuz A, Gil-Peres D, Carvalho AMP, Praia, Vilches A. A necessária renovação no ensino de ciências. São Paulo: Cortez, 2005. 263 p.

Chizzoti A. Pesquisa qualitativa em ciências humanas e sociais: evolução e desafios. Revista Portuguesa de Educação, 2003; 16(2):221-236.

Daza-Caceido S. Imagen de la ciencia y la tecnología entre los estudiantes iberoamericanos. In: Los estudiantes y la ciencia : encuesta a jóvenes iberoamericanos / 
compilado por Carmelo Polino. - 1a ed. - Buenos Aires : Organización de Estados Iberoamericanos para la Educación, la Ciencia y la Cultura, 2011, p.117-154.

Freshi,M; Ramos,M.G. "Unidade de Aprendizagem: um processo em construção que possibilita o trânsito entre senso comum e conhecimento científico." Revista Electrónica de Enseñanza de las Ciencias Vol.8 Nº ,p.156-170 (2009).

Freitas M. Educação Ambiental e /ou educação para o desenvolvimento sustentável? Uma análise centrada na realidade portuguesa. Revista Iberoamericana de Educación, 2006; 41: 133-147.

Galiazzi MC, Garcia F AE, Lindemann RH. (2004). Construindo Caleidoscópios: organizando Unidades de Aprendizagem. En Moraes, R.; Mancuso, R. (2004) Educação em ciências: produção de currículos e formação de professores (pp. 65-84). Ijuí: UNIJUÍ.

Gil-Pérez et al. Para uma imagem não deformada do trabalho científico. Ciência \& Educação, 2001;7(2):125-153.

Gil- Pérez D, Vilches A.. Década de la Educación para un futuro sostenible, En Moreno, J. (Ed.), Didáctica de las ciencias. Nuevas Perspectivas. 2006: 1-21. La Habana: Educación Cubana.

Jacobi, P. Educação ambiental e o desafio da sustentabilidade socioambiental. O mundo da saúde, 2006;.4( 30): 524-531.

Jacobi P. Educar para a Sustentabilidade: complexidade, reflexividade, desafios. Revista Educação e Pesquisa, 2005 Mai/Ago; 31(2),FEUSP.

Jacobi P, Tristão M, Franco MIGC. A função social da educação ambiental nas práticas colaborativas: Participação e engajamento. Cad. Cedes, 2009 Jan/Abr ; 29(77): 63-79.

Lefevre et al, 2007. "Representações sobre dengue, seu vetor e ações de controle por moradores do Município de São Sebastião, Litoral Norte do Estado de São Paulo”, Brasil. Cad. Saúde Pública, 2007 Jul; 23(7):1696-1706.

Oliveira DF. Oficinas Teatrais: estratégia educativa para o diagnóstico de concepções e problemas sobre a prevenção da dengue. Dissertação (Mestrado em Ensino de Biociências e Saúde)-Instituto Oswaldo Cruz; 2006.

Pereira, C.R.S; Passos, N.R.S; Borges, R.M.R. "Unidade de aprendizagem sobre citologia e nanotecnologia: um novo olhar ao século XXI." Experiências em Ensino de Ciências - V3(3), pp. 7-17, 2008

Reis, PGR. Controvérsias sócio-científicas: discutir ou não discutir?: Percursos da aprendizagem da disciplina de ciências da terra e da vida. Tese ( Doutorado em Educação)- Faculdade de Ciências da Universidade de Lisboa; 2004.

Ríos E, Solbes J. Las relaciones CTSA en la enseñanza de la tecnologia y las ciencias: una propuesta con resultados. Revista Electrónica de Enseñanza de las Ciencias , 2007; $6(1)$. 
Sauvé L. Uma cartografia das correntes em educação ambiental. In: SATO, M; CARVALHO, I. Educação ambiental pesquisa e desafios. Porto Alegre: Artmed, 2005.p. 17-44.

Solbes J, Vilches A. Papel de las relaciones entre ciencia, tecnología, sociedad y ambiente en la formación ciudadana. Enseñanza de Las Ciencias, 2004; 3(22): 337-348.

Sperandio TM. Qualidade ambiental e de vida humana: as alterações socioambientais e a difusão da dengue em Piracicaba-SP. Dissertação ( Mestrado em Geociências e Ciências Exatas)-Universidade Estadual Paulista Júlio de Mesquita Filho; 2006.

Tauil P L. Aspectos críticos no controle da dengue. Cad. Saúde Pública, 2002 mai/jun ; 18 (3): 867-871.

Tauil PL. Urbanização e ecologia da dengue. Cad. Saúde Pública, 2001. 17 (suplemento): 99-102.

Teixeira TRA, Medronho, RA. Indicadores sócio-demográficos e a epidemia de dengue em 2002 no estado do Rio de Janeiro, Brasil. Cad. Saúde Pública, 2008 Set; 24(9):

2160-2170.

Vasconcelos ES, Santos WLP. Educação Ambiental por meio de tema CTSA: relato e análise de experiência em sala de aula. In: XIV ENCONTRO NACIONAL DE ENSINO DE QUÍMICA, Curitiba. XIVENEQ. Curitiba: Sociedade Brasileira de Química, 2008. 